\title{
Hemograma de cães submetidos ao envenenamento experimental por Tityus serrulatus
}

\author{
[Canine blood profile after experimental envenomation \\ by Tityus serrulatus] \\ E.L. Ribeiro, M.M. Melo*, M.C.L. Pinto, C.R. Labarrère, P.T.C. Guimarães, \\ P.R.O. Paes, F.O.P. Leme \\ Escola de Veterinária - UFMG \\ Caixa Postal 567 \\ 30123-970 - Belo Horizonte, MG
}

\begin{abstract}
RESUMO
Avaliou-se o hemograma de 12 cães adultos, saudáveis $(14,2 \pm 5,4 \mathrm{~kg})$ após a inoculação de veneno do escorpião amarelo (Tityus serrulatus). Os animais foram distribuídos em dois grupos (G), com seis em cada: os do GI foram usados como controle e receberam $0,5 \mathrm{~mL}$ de salina tamponada com fosfato (PBS) por via subcutânea (SC) na face medial da coxa esquerda (FMCE), e os do GII receberam veneno liofilizado do T. serrulatus $(250 \mu \mathrm{g} / \mathrm{kg}$ ) diluído em PBS por via SC na FMCE. Foram realizadas colheitas de sangue com anticoagulante EDTA a 10\% antes da inoculação do veneno (T0) e após $2 \mathrm{~h}$, (T1), $6 \mathrm{~h}$ (T2), 12h (T3), 24h (T4), 48h (T5) e 72h (T6), para contagem de eritrócitos, leucócitos e plaquetas em aparelho contador eletrônico e esfregaços sanguíneos para contagem diferencial de leucócitos. Houve aumento significativo $(\mathrm{P}<0,05)$ dos valores de eritrócitos, volume globular e hemoglobina $2 \mathrm{~h}$ e $6 \mathrm{~h}$ após o envenenamento, devido à contração esplênica decorrente da dor local causada pelo veneno e pela liberação de catecolaminas. Foi observada leucocitose por aumento significativo $(\mathrm{P}<0,05)$ de neutrófilos e linfócitos $2 \mathrm{~h}$ e $6 \mathrm{~h}$ após o envenenamento. Concluiu-se que o veneno de Tityus serrulatus na dose de $250 \mu \mathrm{g} / \mathrm{kg}$, é capaz de aumentar os valores do eritrograma e do leucograma dos cães, provavelmente devido à dor local, com liberação de catecolaminas.
\end{abstract}

Palavras-chave: cão, escorpionismo, Tityus serrulatus, hematologia

\begin{abstract}
The canine blood profile after scorpion envenomation was evaluated using 12 healthy mongrel male dogs (14.2 $\pm 5.4 \mathrm{~kg})$ distributed in two groups, with six animals in each: group I (control group) and group II (venom group). The lyophilized yellow scorpion (Tityus serrulatus) venom $(250 \mu \mathrm{g} / \mathrm{kg})$ diluted in $0.5 \mathrm{~mL}$ phosphate buffered saline (PBS) was given to group II animals by subcutaneous injection, in the medial face of the left thigh. Group I animals received only 0.5mL of PBS, by subcutaneous injection, in the medial face of the left thigh. Blood samples were collected with EDTA before (T0) and 2 (T1), 6 (T2), 12 (T3), 24 (T4), 48 (T5), and $72 h$ (T6) after envenomation. Significant increases $(P<0.05)$ in erythrocytes counting, hematocrit and hemoglobin concentration, 2 and $6 h$ after envenomation were observed. Leukocytosis with significant increases $(P<0.05)$ of neutrophils and lymphocytes 2 and $6 \mathrm{~h}$ after envenomation was found. Then, T. serrulatus venom may induce alterations in blood profile in dogs, probably due to spleen contraction evoked by pain and catecholamines releasing.
\end{abstract}

Keywords: dog, envenomation, Tityus serrulatus, blood profile

Recebido em 10 de outubro de 2008

Aceito em 30 de janeiro de 2009

*Autor para correspondência (corresponding author)

E-mail: marilia@vet.ufmg.br 


\section{INTRODUÇÃO}

Os dados do Ministério da Saúde indicam que ocorrem cerca de 8000 acidentes por ano, no Brasil, com um coeficiente de incidência de três casos para cada 100.000 habitantes (Manual..., 2001). Cerca de $50 \%$ dos acidentes são diagnosticados nos estados de Minas Gerais e São Paulo, mas tem-se registrado aumento de notificações provenientes da Bahia, Rio Grande do Norte, Alagoas e Ceará (Manual..., 2001; Soares et al., 2002; Cupo et al., 2003). Todavia, não se sabe qual $o$ número de animais domésticos, especialmente o cão, picados por escorpiões. Estima-se que seja elevado, pois o cão doméstico divide com o homem o mesmo ambiente.

Os escorpiões vivem em locais de clima tropical e são muito adaptados ao ambiente urbano, onde têm alimentação farta e sem competição (Bücherl, 1969). O escorpião da espécie Tityus serrulatus é o mais prevalente e envolvido em mais de 95\% dos acidentes (Soares et al., 2002; Campolina, 2006).

O veneno de escorpiões é caracterizado pela variedade e complexidade de toxinas, e apenas nos da família Buthidae há espécies que produzem neurotoxinas. $\mathrm{O}$ número total de diferentes toxinas produzidas por escorpiões é estimado em 100.000, das quais, apenas $1 \%$ é conhecido. A composição química individual do veneno de cada espécie, no entanto, não é tão complexa quanto à de venenos de serpentes (Oliveira et al., 2007). É composto basicamente por proteínas de baixo peso molecular com cadeias curtas de aminoácidos, mucopolissacarídeos, pequenas quantidades de hialuronidases e neurotoxinas, sem atividade hemolítica, proteolítica, colinesterásica, fosfolipásica e fibrinogenolítica (Cupo et al., 2003; Gazarian et al., 2005).

O mecanismo de ação do veneno escorpiônico envolve a ligação de toxina em canais de sódio pós-ganglionares, com função estimuladora sendo descritas toxinas vontagem-dependente ou não; como a função é estimuladora, o sódio entra na célula. Outras proteínas ligam-se a canais de potássio pós-ganglionares, mas com função bloqueadora, ou seja, não permitem o retorno do potássio para a célula, que se acumula no meio extracelular. O resultado é a despolarização da membrana, potencial de ação e liberação de catecolaminas (adrenalina e noradrenalina) e acetilcolina pelas terminações neuronais nas sinapses. (Ismail, 1995; Gazarian et al.; 2005). Portanto, dependendo do neurotransmissor liberado e da fibra nervosa, os efeitos podem ser adrenérgicos ou colinérgicos. Entre os efeitos mais graves, destacam-se as alterações cardiovasculares, com miocardite e insuficiência cardíaca congestiva, edema pulmonar e hipertensão arterial (Ismail, 1995; Cupo et al., 2003).

Leucocitose com neutrofilia foi relatada em humanos com quadro de envenenamento escorpiônico (Bucaretchi et al., 1995; Cupo e Hering, 2002), e estudos com animais de laboratório demonstraram aumento do hematócrito, decorrente de hemoconcentração advinda de perdas hídricas, sobretudo pelo aumento de secreções do trato gastrintestinal devido ao efeito parassimpático da acetilcolina, causando vômitos, diarreia e sialorreia (Andrade et al., 2004). Bertazzi et al. (2003) também observaram aumento do hematócrito sendo esse atribuído ao aumento das proteínas de fase aguda do processo inflamatório.

O objetivo deste trabalho foi caracterizar o perfil hematológico de cães após a inoculação experimental do veneno de $T$. serrulatus.

\section{MATERIAL E MÉTODOS}

Foi utilizado um pool de venenos de vários escorpiões da espécie Tityus serrulatus capturados na região de Belo Horizonte (MG), gentilmente cedido pelo professor ChávezOlórtegui ${ }^{1}$. A concentração de $250 \mu \mathrm{g} / \mathrm{kg}$ de veneno de $T$. serrulatus foi determinada, previamente, em um experimento-piloto, e diluída em $0,5 \mathrm{~mL}$ de solução salina tamponada com fosfato (PBS).

Foram utilizados 12 cães sem raça definida, machos, adultos, saudáveis $(14,2 \pm 5,4 \mathrm{~kg})$ com sorologia negativa para leishmaniose ${ }^{2}$, cedidos pelos Centros de Controle de Zoonoses de Belo

${ }^{1}$ Professor Carlos Delfín Chávez-Olórtegui - Instituto de Ciências Biológicas - UFMG.

${ }^{2}$ ELISA e RIFI - Professor Élvio Carlos Moreira - Escola de Veterinária - UFMG. 
Horizonte e Betim (MG). Os cães, após passarem por quarentena de 15 dias, período em que foram examinados, banhados ${ }^{3}$, desverminados ${ }^{4}$, tratados contra ectoparasitas ${ }^{5}$ e vacinados ${ }^{6}$, foram abrigados em canis individuais $(2 \mathrm{~m}$ x $3 \mathrm{~m})$ com solário onde receberam dieta à base de ração canina comercial e água à vontade.

Os animais foram distribuídos aleatoriamente em dois grupos $(\mathrm{G})$, com seis cães em cada: os do GI foram usados como controle e receberam $0,5 \mathrm{~mL}$ de salina tamponada com fosfato (PBS) por via subcutânea (SC) na face medial da coxa esquerda (FMCE), e os do GII receberam veneno liofilizado do $T$. serrulatus $(250 \mu \mathrm{g} / \mathrm{kg})$ diluído em PBS por via SC na FMCE. Para inoculação do PBS (placebo) e do veneno diluído em PBS, utilizou-se seringa hipodérmica descartável de $1,0 \mathrm{~mL}$ para insulina, com dispositivo de esparadrapo adaptado à agulha para mimetizar o aguilhão do escorpião.

Amostras de sangue foram colhidas antes do envenenamento (T0) e após 2h (T1), 6h (T2), 12h (T3), 24h (T4), 48h (T5) e 72h (T6). As colheitas foram feitas por venopunção jugular ou cefálica com agulha para colheita a vácuo ${ }^{7}$ antecedida por anti-sepsia local com álcool iodado. O sangue foi colhido em tubos de $3 \mathrm{~mL}^{8}$ contendo sal dissódico do ácido etilenodiaminotetracético (EDTA) a 10\% e sem anticoagulante para obtenção do soro.

O hemograma foi realizado da seguinte forma: (a) contagem de hemácias, determinação da hemoglobina, volume globular, contagem total de leucócitos e plaquetas foram processados em contador eletrônico ${ }^{9}$; (b) contagem diferencial de leucócitos e observação morfológica das células sanguíneas, foram realizadas em esfregaços sanguíneos em lâminas de vidro $(26 \times 76 \mathrm{~mm})^{10}$ corados com May Grunwald - Giemsa ${ }^{11}$. A dosagem sérica de proteínas totais (PT) foi feita

\footnotetext{
${ }^{3}$ Shampoo Sanol Dog - Total Química - Embu, Brasil.

${ }^{4}$ Helfine Cães - Agener União - São Paulo, Brasil.

${ }^{5}$ TopLine RED - Merial Saúde Animnal

${ }^{6}$ Vanguard - Pfizer Saúde Animal - Guarulhos, Brasil.

${ }^{7}$ Labor Import - Osasco, Brasil

${ }^{8}$ Greiner Bio-One Brasil - Americana, Brasil.

${ }^{9}$ CELM DA-500 - CELM, Cia. Equipadora de Laboratórios

Modernos - Barueri, Brasil.

${ }^{10}$ Lâminas para microscopia Exacta - Perfecta - São Paulo, Brasil.

${ }^{11}$ May Grunwald/Giemsa - Doles Reagentes - Goiânia,

Brasil.
}

por método colorimétrico cinético ${ }^{12}$ em aparelho analisador bioquímico ${ }^{13}$.

O delineamento experimental aplicado foi $\mathrm{o}$ inteiramente ao acaso, em esquema de parcelas subdivididas, conforme Sampaio (2007). As parcelas correspondem aos tratamentos (controle e veneno) e as subparcelas, aos tempos, em horas. Os dados referentes aos diferentes grupos e tempos foram plotados em tabelas e analisados pelos programas SAS/1985 e SAEG (Sistema..., 1998). Foram realizados os testes de normalidade (Lillifors, Kolmogorov-Smirnov e Shapiro-Wilk) e, para as variáveis que apresentaram distribuição normal (algumas delas após sofrer transformação logarítmica $(\log 10 \mathrm{x}+1)$, foi realizada a análise de variância e a comparação de médias pelo teste Tukey.

O projeto de pesquisa foi aprovado pelo CETEA - Comitê de Ética em Experimentação Animal da UFMG, com o número de protocolo 15/2006, em 12 de julho de 2006.

\section{RESULTADOS E DISCUSSÃO}

O número de hemácias e o volume globular (VG) dos animais dos grupos I e II são apresentados na Tab.1. No grupo II, ocorreu aumento de $16 \%$ no T1 $(\mathrm{P}<0,05)$, tanto no número de hemácias quanto no VG. No T2, $6 \mathrm{~h}$ após o envenenamento, esses valores já haviam diminuído, mas ainda eram diferentes dos valores de T0 e dos tempos seguintes. Em T3, retornaram aos valores basais. No grupo I (controle), não houve diferenças entre os tempos para essas variáveis, mas a contagem de hemácias de T1 e T2 do grupo de animais envenenados foi significativamente maior que a do grupo-controle. A concentração de hemoglobina (Tab. 2) apresentou variação muito semelhante, sem alterações no grupo I e aumento de $16 \%$ em T1 no grupo II, e também diferente do valor de $\mathrm{T} 1$ do grupo I $(\mathrm{P}<0,05)$. A concentração de hemoglobina retornou aos valores basais $12 \mathrm{~h}$ após, em T3. A concentração de proteínas totais, apresentada na Tab. 2, não diferiu entre grupos e tempos $(\mathrm{P}>0,05)$.

\footnotetext{
${ }^{12}$ Synermed International Inc. - Westfield, EUA

${ }^{13}$ Cobas Mira (Roche-GMI) - Global Medical

Instrumentations, Inc. - Ramsey, EUA.
} 
Os valores médios de hemácias, VG e hemoglobina apresentaram discretos aumentos. Porém, dos seis cães envenenados, duas horas após a inoculação do veneno, três apresentaram aumento significativo no número de hemácias (cão 2 : $8,34 \times 10^{6} / \mu \mathrm{L}$; cão 3 : $8,15 \times 10^{6} / \mu \mathrm{L}$ e cão 6: 9,24 X 10\% $/ \mu \mathrm{L}$ ); no VG (cão 3: $47 \%$ e cão 6: $58 \%$ ) e na concentração de hemoglobina (cão 3: $16,2 \mathrm{~g} / \mathrm{dL}$ e cão 6: $20,3 \mathrm{~g} / \mathrm{dL})$. Não houve diferença $(\mathrm{P}>0,05)$ entre os índices hematimétricos (Tab. 3).

Tabela 1. Valores médios de hemácias e volume globular de cães inoculados com placebo (grupo I) e com veneno de Tityus serrulatus (grupo II) em diferentes tempos

\begin{tabular}{|c|c|c|c|c|}
\hline \multirow{2}{*}{ Tempo } & \multicolumn{2}{|c|}{ Hemácias $\left(\times 10^{6} / \mu \mathrm{L}\right)$} & \multicolumn{2}{|c|}{ Volume globular (\%) } \\
\hline & Grupo I & Grupo II & Grupo I & Grupo II \\
\hline T zero & $6,54 \pm 0,67 \mathrm{Aa}$ & $6,42 \pm 0,70 \mathrm{Abc}$ & $44,1 \pm 3,8 \mathrm{Aa}$ & $38,5 \pm 4,4 \mathrm{Bc}$ \\
\hline $\mathrm{T} 1-2 \mathrm{~h}$ & $6,07 \pm 0,58 \mathrm{Ba}$ & $7,50 \pm 1,46 \mathrm{Aa}$ & $40,8 \pm 2,6 \mathrm{Aa}$ & $45,0 \pm 7,8 \mathrm{Aa}$ \\
\hline $\mathrm{T} 2-6 \mathrm{~h}$ & $6,26 \pm 0,66 \mathrm{Ba}$ & $7,03 \pm 1,22 \mathrm{Aab}$ & $42,1 \pm 3,4 \mathrm{Aa}$ & $43,6 \pm 7,2 \mathrm{Aab}$ \\
\hline $\mathrm{T} 3-12 \mathrm{~h}$ & $6,19 \pm 0,78 \mathrm{Aa}$ & $6,45 \pm 1,13 \mathrm{Abc}$ & $40,8 \pm 2,4 \mathrm{Aa}$ & $40,1 \pm 5,8 \mathrm{Abc}$ \\
\hline $\mathrm{T} 4-24 \mathrm{~h}$ & $6,33 \pm 0,72 \mathrm{Aa}$ & $5,99 \pm 1,17 \mathrm{Ac}$ & $42,0 \pm 2,9 \mathrm{Aa}$ & $37,6 \pm 5,7 \mathrm{Ac}$ \\
\hline $\mathrm{T} 5-48 \mathrm{~h}$ & $6,05 \pm 0,43 \mathrm{Aa}$ & $5,69 \pm 0,89 \mathrm{Ac}$ & $40,0 \pm 3,8 \mathrm{Aa}$ & $35,6 \pm 5,1 \mathrm{Ac}$ \\
\hline $\mathrm{T} 6-72 \mathrm{~h}$ & $6,40 \pm 0,55 \mathrm{Aa}$ & $5,74 \pm 0,62 \mathrm{Ac}$ & $42,8 \pm 4,4 \mathrm{Aa}$ & $37,0 \pm 3,5 \mathrm{Ac}$ \\
\hline
\end{tabular}

Médias seguidas por letras maiúsculas distintas diferem entre os grupos (linhas) e seguidas por letras minúsculas distintas diferem entre os tempos (colunas), pelo teste Tukey $(\mathrm{P}<0,05)$.

Tabela 2. Valores médios das concentrações de hemoglobina e de proteínas totais de cães inoculados com placebo (grupo I) e com veneno de Tityus serrulatus (grupo II) em diferentes tempos

\begin{tabular}{|c|c|c|c|c|}
\hline \multirow{2}{*}{ Tempo } & \multicolumn{2}{|c|}{ Hemoglobina (g/dL) } & \multicolumn{2}{|c|}{ Proteínas Totais $(\mathrm{g} / \mathrm{dL})$} \\
\hline & Grupo I & Grupo II & Grupo I & Grupo II \\
\hline T zero & $14,30 \pm 1,47 \mathrm{Aa}$ & $13,15 \pm 1,88$ Acd & $6,22 \pm 0,75 \mathrm{Aa}$ & $7,08 \pm 0,95 \mathrm{Aa}$ \\
\hline $\mathrm{T} 1-2 \mathrm{~h}$ & $13,30 \pm 1,13 \mathrm{Ba}$ & $15,25 \pm 3,03 \mathrm{Aa}$ & $5,95 \pm 0,83 \mathrm{Aa}$ & $7,10 \pm 1,06 \mathrm{Aa}$ \\
\hline $\mathrm{T} 2-6 \mathrm{~h}$ & $14,01 \pm 1,10 \mathrm{Aa}$ & $14,55 \pm 2,60 \mathrm{Aab}$ & $6,32 \pm 0,76 \mathrm{Aa}$ & $7,22 \pm 1,17 \mathrm{Aa}$ \\
\hline $\mathrm{T} 3-12 \mathrm{~h}$ & $13,78 \pm 1,19 \mathrm{Aa}$ & $13,70 \pm 2,22 \mathrm{Abc}$ & $6,20 \pm 0,70 \mathrm{Aa}$ & $7,12 \pm 0,94 \mathrm{Aa}$ \\
\hline $\mathrm{T} 4-24 \mathrm{~h}$ & $13,58 \pm 1,28 \mathrm{Aa}$ & $12,55 \pm 1,92 \mathrm{Acd}$ & $6,10 \pm 0,72 \mathrm{Aa}$ & $6,95 \pm 0,91 \mathrm{Aa}$ \\
\hline $\mathrm{T} 5-48 \mathrm{~h}$ & $13,20 \pm 0,74 \mathrm{Aa}$ & $12,03 \pm 1,76 \mathrm{Ad}$ & $5,82 \pm 0,30 \mathrm{Aa}$ & $6,90 \pm 1,56 \mathrm{Aa}$ \\
\hline $\mathrm{T} 6-72 \mathrm{~h}$ & $14,08 \pm 1,35 \mathrm{Aa}$ & $12,62 \pm 1,29$ Acd & $6,23 \pm 0,77 \mathrm{Aa}$ & $6,97 \pm 1,47 \mathrm{Aa}$ \\
\hline
\end{tabular}

Médias seguidas por letras maiúsculas distintas diferem entre os grupos (linhas) e seguidas por letras minúsculas distintas diferem entre os tempos (colunas), pelo teste Tukey $(\mathrm{P}<0,05)$.

Tabela 3. Valores médios de hemoglobina globular média (HGM), volume globular médio (VGM) e concentração de hemoglobina globular média (CHGM) de cães inoculados com placebo (grupo I) e com veneno de Tityus serrulatus (grupo II) em diferentes tempos

\begin{tabular}{lcccccc}
\hline \multirow{2}{*}{ Tempo } & \multicolumn{2}{c}{ HGM (pg) } & \multicolumn{2}{c}{ VGM (g/dL) } & \multicolumn{2}{c}{ CHGM (fl) } \\
\cline { 2 - 6 } & Grupo I & Grupo II & Grupo I & Grupo II & Grupo I & Grupo II \\
\hline T zero & $21,8 \pm 1,4$ & $20,4 \pm 1,8$ & $67,6 \pm 3,9$ & $60,1 \pm 5,3$ & $32,3 \pm 0,7$ & $33,7 \pm 2,1$ \\
T1 - 2h & $22,0 \pm 0,9$ & $20,4 \pm 1,8$ & $67,5 \pm 4,6$ & $60,5 \pm 6,4$ & $32,5 \pm 1,2$ & $33,7 \pm 1,3$ \\
T2 - 6h & $22,4 \pm 0,9$ & $20,7 \pm 1,5$ & $67,5 \pm 5,2$ & $62,2 \pm 3,8$ & $33,2 \pm 1,5$ & $33,2 \pm 1,3$ \\
T3 - 12h & $22,3 \pm 1,1$ & $21,3 \pm 1,6$ & $66,6 \pm 7,9$ & $62,6 \pm 6,1$ & $33,7 \pm 2,7$ & $34,1 \pm 2,7$ \\
T4 - 24h & $21,6 \pm 0,8$ & $21,1 \pm 1,8$ & $66,6 \pm 2,9$ & $63,4 \pm 6,9$ & $32,5 \pm 1,1$ & $33,3 \pm 1,7$ \\
T5 - 48h & $21,9 \pm 1,5$ & $21,2 \pm 1,8$ & $66,1 \pm 5,0$ & $62,8 \pm 4,3$ & $33,1 \pm 2,3$ & $33,7 \pm 1,8$ \\
T6 - 72h & $21,9 \pm 1,3$ & $21,9 \pm 0,7$ & $67,0 \pm 6,5$ & $64,5 \pm 3,8$ & $32,9 \pm 2,2$ & $34,1 \pm 2,0$ \\
\hline
\end{tabular}

Não houve diferença significativa entre tempos e entre grupos submetidos à transformação logarítmica e à análise de variância e ao teste Tukey $(\mathrm{P}>0,05)$.

Policitemias podem ser relativas ou absolutas e envolvem aumentos nos valores de hemácias, $\mathrm{VG}$ e hemoglobina. Um $\mathrm{VG}$ de $50 \%$ torna o sangue mais viscoso, o que dificulta o transporte de oxigênio e, quando esse valor ultrapassa $60 \%$, é considerado policitemia. Aumentos agudos 
nesses valores retornando à normalidade rapidamente, com a correção da causa, caracterizam as policitemias relativas, que podem ser consequências de dois mecanismos distintos: (1) diminuição de volume plasmático, causado por desidratação, levando ao aumento do VG, mas não alterando a massa total de eritrócitos circulantes; (2) contração esplênica, após estresse ou dor, com injeção temporária de grande massa de eritrócitos na corrente sanguínea (Jain, 1993).

As alterações citadas, provavelmente ocorreram por contração esplênica, em função da dor e da ação de catecolaminas sobre o baço. Os cães 2 e 6 , que apresentaram, individualmente, altas contagens de hemácias e VG, foram, coincidentemente, os que apresentaram episódio emético após a inoculação do veneno. $\mathrm{O}$ cão 2 vomitou 3,5h após o envenenamento, descartando-se o efeito da diminuição do volume plasmático, pois o aumento de $\mathrm{VG}$ aconteceu $2 \mathrm{~h}$ após o envenenamento (T1) e antes do episódio emético, levando à suposição de que o aumento das proteínas de fase aguda (Fagliari et al., 2007, 2008; Saquetti et al., 2008) tenha contribuído com o aumento do VG, semelhante ao observado por Bertazzi et al. (2003). O cão 6, no entanto, apresentou emese $1 \mathrm{~h}$ após a inoculação, fazendo supor que a discreta desidratação do animal (abaixo de 5\%, sem manifestação clínica) possa ter se somado aos efeitos da contração esplênica observada em T1. Ressalta-se que os cães 2 e 6 também foram os únicos a manifestar dor abdominal. O retorno desses parâmetros aos valores normais ocorreu entre 6 e $12 \mathrm{~h}$ após, coincidindo com o período de eliminação do veneno.
A contração esplênica pode causar aumento no hematócrito em consequência do efeito simpatoadrenal evocado pelo veneno escorpiônico. Andrade et al. (2004) realizaram uma avaliação completa dos níveis plasmáticos de eletrólitos e do balanço ácido-básico em ratos e observaram aumento significativo de hematócrito 60 minutos após inoculação de veneno de $T$. serrulatus. O efeito da contração esplênica em cães, após o envenenamento escorpiônico (Leirus quinquestriatus), foi estudado por Tarasiuk e Sofer (1999), após bloqueio de receptores adrenérgicos esplênicos e ligaduras em vasos sanguíneos do baço, demonstrando-se que a contração esplênica ocorre em razão do efeito das catecolaminas. Bertazzi et al. (2003), ao avaliarem o hematócrito em ratos, após a inoculação de veneno bruto de $T$. serrulatus e de sua toxina mais importante, a TsTX-I, observaram hemoconcentração atribuída às perdas de líquidos por salivação, lacrimejamento e micção, e ao aumento das proteínas de fase aguda do processo inflamatório.

A contagem de plaquetas diferiu entre tempos apenas no grupo-controle $(\mathrm{P}<0,05)$, porém, todos os valores encontrados (Tab. 4) enquadram-se dentro da margem de referência para a espécie canina $\left(150-500 \times 10^{3} / \mu \mathrm{L}\right)$, segundo Jain (1993). A variação encontrada foi muito discreta, caracterizada por diminuição gradativa até $12 \mathrm{~h}$. Provavelmente, isso ocorreu em função da colheita de sangue realizada em intervalos muito curtos.

Tabela 4. Valores médios de plaquetas de cães inoculados com placebo (grupo I) e com veneno de Tityus serrulatus em diferentes tempos

\begin{tabular}{ccc}
\hline & Plaquetas $\left(\times 10^{3} / \mu \mathrm{L}\right)$ & \\
\hline Tempo & Grupo I & Grupo II \\
\hline T zero & $296,5 \pm 62,5 \mathrm{Aa}$ & $233,0 \pm 58,8 \mathrm{Ba}$ \\
T1 $-2 \mathrm{~h}$ & $280,6 \pm 74,1 \mathrm{Aab}$ & $225,6 \pm 70,5 \mathrm{Aa}$ \\
T2 $-6 \mathrm{~h}$ & $263,6 \pm 76,2 \mathrm{Aab}$ & $210,5 \pm 44,3 \mathrm{Aa}$ \\
T3 $-12 \mathrm{~h}$ & $220,3 \pm 39,2 \mathrm{Ab}$ & $253,1 \pm 76,5 \mathrm{Aa}$ \\
T4 $-24 \mathrm{~h}$ & $241,6 \pm 88,5 \mathrm{Aab}$ & $227,0 \pm 49,0 \mathrm{Aa}$ \\
T5 $-48 \mathrm{~h}$ & $261,0 \pm 47,8 \mathrm{Aab}$ & $240,6 \pm 53,3 \mathrm{Aa}$ \\
T6 $-72 \mathrm{~h}$ & $270,1 \pm 70,2 \mathrm{Aab}$ & $222,3 \pm 36,3 \mathrm{Aa}$ \\
\hline
\end{tabular}

Médias seguidas por letras maiúsculas distintas diferem entre os grupos (linhas) e seguidas por letras minúsculas distintas diferem entre os tempos (colunas), pelo teste Tukey $(\mathrm{P}<0,05)$. 
A agregação plaquetária e a síndrome de coagulação intravascular disseminada em cães foram relatadas no envenenamento escorpiônico por Centruroides sculpturatus causada por frações não-neurotóxicas do veneno que estimularam a liberação do fator de agregação plaquetária (PAF), além de, possivelmente, serem indutoras de "síndrome de desfibrinação" (Longenecker e Longeneker, 1981). Além disso, sabe-se que a agregação plaquetária pode ser provocada pela adrenalina (El-Asmar, 1984; Dodds, 1997). Apesar de no presente trabalho não terem sido avaliadas a hemostasia e a função plaquetária dos cães, supõe-se que a contagem estável de plaquetas nos animais envenenados associada à ausência de sinais de hemorragia indiquem que nem o veneno de Tityus serrulatus nem a descarga de catecolaminas causaram agregação, consumo de plaquetas e anormalidades na coagulação sanguínea.

A contagem de leucócitos totais encontra-se na Tab. 5. Houve aumento significativo $(\mathrm{P}<0,05)$ em T1 e T2 no GII. Em T3, o valor era menor, mas só em T4, 24h após o envenenamento, o número de leucócitos voltou aos valores iniciais. No GI, não houve diferenças entre os tempos, mas os valores encontrados em $\mathrm{T} 1$ e $\mathrm{T} 2$ foram estatisticamente mais baixos que os do GII. A contagem diferencial dos leucócitos em esfregaços sanguíneos mostrou que o aumento no número de leucócitos totais foi devido, principalmente, ao aumento de neutrófilos e linfócitos (Tab. 6).

De maneira semelhante à contagem de leucócitos totais, a contagem de neutrófilos não diferiu entre tempos no GI, mas foi maior $(\mathrm{P}<0,05)$ no GII, em T1 e T2. Em T3, o valor médio diminuiu, mas só em T4 voltou a ser semelhante ao valor inicial. $\mathrm{O}$ número de linfócitos apresentou, no GII, o maior valor em T1, diferente estatisticamente do valor do mesmo tempo no GI. Porém, em nenhum dos tempos houve contagem média diferente da contagem do T0.

Tabela 5. Valores médios de leucócitos totais de cães inoculados com placebo (grupo I) e com veneno de Tityus serrulatus (grupo II) em diferentes tempos

\begin{tabular}{lcc}
\hline & Leucócitos totais $\left(\mathrm{x} 10^{3} / \mu \mathrm{L}\right)$ & \\
\hline Tempo & Grupo I & Grupo II \\
\hline T zero & $10,80 \pm 2,57 \mathrm{Aa}$ & $10,75 \pm 2,73 \mathrm{Ac}$ \\
T1 $-2 \mathrm{~h}$ & $9,88 \pm 1,31 \mathrm{Ba}$ & $17,81 \pm 2,68 \mathrm{Aa}$ \\
T2 $-6 \mathrm{~h}$ & $12,23 \pm 3,30 \mathrm{Ba}$ & $18,25 \pm 5,46 \mathrm{Aa}$ \\
T3 $-12 \mathrm{~h}$ & $12,19 \pm 2,54 \mathrm{Aa}$ & $15,41 \pm 5,58 \mathrm{Aab}$ \\
T4 $-24 \mathrm{~h}$ & $9,76 \pm 2,00 \mathrm{Aa}$ & $12,02 \pm 5,09 \mathrm{Abc}$ \\
T5 $-48 \mathrm{~h}$ & $10,30 \pm 2,46 \mathrm{Aa}$ & $11,64 \pm 4,95 \mathrm{Ac}$ \\
T6 $-72 \mathrm{~h}$ & $11,13 \pm 1,93 \mathrm{Aa}$ & $11,99 \pm 3,85 \mathrm{Abc}$ \\
\hline
\end{tabular}

Médias seguidas por letras maiúsculas distintas diferem entre os grupos (linhas) e seguidas por letras minúsculas distintas diferem entre os tempos (colunas), pelo teste Tukey $(\mathrm{P}<0,05)$.

$\mathrm{Na}$ contagem diferencial de leucócitos, não foram encontrados neutrófilos jovens, tanto no GI quanto no GII. Esse fato, aliado à rapidez com que o número médio de neutrófilos se elevou $(2 \mathrm{~h})$ e retornou ao valor inicial $(24 \mathrm{~h})$, indica que a leucocitose é fisiológica. Nos cães, o compartimento marginal dos neutrófilos é igual ao compartimento circulante. A liberação súbita de neutrófilos desse compartimento ocorre após refeições, na gestação, após exercícios intensos ou prolongados, vômitos, convulsões e no estresse por mediação de catecolaminas (Jain, 1993). A leucocitose com neutrofilia foi relatada em diversos acidentes escorpiônicos com humanos (Bucaretchi et al., 1995; Cupo e Hering, 2002; Cupo et al., 2003) e em apenas um relato de caso em cão (Cordeiro et al., 2006). Os resultados deste experimento indicam neutrofilia causada pela dor, pelo estresse e pelo efeito neurotóxico do veneno de T.serrulatus, pois ambos causam a liberação de catecolaminas. Ressalta-se, também, a descrição de uma reação inflamatória aguda, com aumento no teor de citocinas pró-inflamatórias, como IL-1, IL-2 e IL-6, interleucinas já relatadas como atuantes na "síndrome do envenenamento escorpiônico" (Meki e El-Dean, 1998; Magalhães et al., 1999; D'Suze et al., 2003; Fukuhara et al., 2003; Petrievich et al., 2007). Supõe-se que o retorno gradativo aos valores iniciais entre $6 \mathrm{~h}$ e $12 \mathrm{~h}$ seja condizente com a eliminação do veneno circulante. 
Tabela 6. Valores médios de neutrófilos e linfócitos de cães inoculados com placebo (grupo I) e com veneno de Tityus serrulatus (grupo II) em diferentes tempos

\begin{tabular}{lcccc}
\hline \multirow{2}{*}{ Tempo } & \multicolumn{2}{c}{ Neutrófilos $\left(\times 10^{3} / \mu \mathrm{L}\right)$} & \multicolumn{2}{c}{ Linfócitos $\left(\mathrm{x} 10^{3} / \mu \mathrm{L}\right)$} \\
\cline { 2 - 5 } & Grupo I & Grupo II & Grupo I & Grupo II \\
\hline T zero & $7,72 \pm 2,15 \mathrm{Aa}$ & $7,38 \pm 1,91 \mathrm{Ac}$ & $1,48 \pm 0,57 \mathrm{Aa}$ & $1,96 \pm 1,20 \mathrm{Aab}$ \\
T1 $-2 \mathrm{~h}$ & $6,80 \pm 0,96 \mathrm{Ba}$ & $12,92 \pm 2,00 \mathrm{Aa}$ & $1,44 \pm 0,59 \mathrm{Ba}$ & $2,89 \pm 1,29 \mathrm{Aa}$ \\
T2 $-6 \mathrm{~h}$ & $8,97 \pm 2,57 \mathrm{Ba}$ & $14,38 \pm 5,00 \mathrm{Aa}$ & $1,38 \pm 0,31 \mathrm{Aa}$ & $2,18 \pm 0,88 \mathrm{Aab}$ \\
T3 $-12 \mathrm{~h}$ & $8,84 \pm 1,98 \mathrm{Aa}$ & $11,95 \pm 4,59 \mathrm{Aab}$ & $1,55 \pm 0,36 \mathrm{Aa}$ & $1,76 \pm 0,77 \mathrm{Ab}$ \\
T4 $-24 \mathrm{~h}$ & $6,79 \pm 1,42 \mathrm{Aa}$ & $8,96 \pm 3,62 \mathrm{Abc}$ & $1,38 \pm 0,62 \mathrm{Aa}$ & $1,67 \pm 1,11 \mathrm{Ab}$ \\
T5 $-48 \mathrm{~h}$ & $6,78 \pm 2,10 \mathrm{Aa}$ & $8,26 \pm 2,89 \mathrm{Ac}$ & $1,52 \pm 0,51 \mathrm{Aa}$ & $2,02 \pm 1,86 \mathrm{Ab}$ \\
T6 $-72 \mathrm{~h}$ & $7,35 \pm 2,14 \mathrm{Aa}$ & $8,76 \pm 2,44 \mathrm{Abc}$ & $1,91 \pm 0,90 \mathrm{Aa}$ & $1,50 \pm 0,87 \mathrm{Ab}$ \\
\hline
\end{tabular}

Médias seguidas por letras maiúsculas distintas diferem entre os grupos (linhas) e seguidas por letras minúsculas distintas diferem entre os tempos (colunas), pelo teste Tukey $(\mathrm{P}<0,05)$.

Mesmo com a diferença observada entre os valores médios de linfócitos entre os grupos (Tab. 6), após a inoculação do veneno, os valores encontram-se dentro dos limites de normalidade para cão, segundo Jain (1993). Essa resposta, provavelmente, pode ser atribuída à contração dos vasos linfáticos.
Não foram encontrados basófilos nos esfregaços sanguíneos. As contagens de monócitos e eosinófilos (Tab. 7) não diferiram entre tempos e entre grupos $(\mathrm{P}>0,05)$.

Tabela 7. Valores médios de monócitos e eosinófilos de cães inoculados com placebo (grupo I) e com veneno de Tityus serrulatus (grupo II) em diferentes tempos

\begin{tabular}{lcccc}
\hline \multirow{2}{*}{ Tempo } & \multicolumn{2}{c}{ Monócitos $\left(\times 10^{3} / \mu \mathrm{L}\right)$} & \multicolumn{2}{c}{ Eosinófilos $\left(\times 10^{3} / \mu \mathrm{L}\right)$} \\
\cline { 2 - 5 } & \multicolumn{1}{c}{ Grupo I } & Grupo II & Grupo I & Grupo II \\
\hline T zero & $0,63 \pm 0,26$ & $0,66 \pm 0,28$ & $0,96 \pm 0,41$ & $0,70 \pm 0,51$ \\
T1 - 2h & $0,62 \pm 0,18$ & $1,03 \pm 0,46$ & $1,00 \pm 0,74$ & $0,98 \pm 0,66$ \\
T2 - 6h & $0,81 \pm 0,27$ & $0,81 \pm 0,37$ & $1,05 \pm 0,57$ & $0,88 \pm 0,66$ \\
T3-12h & $0,76 \pm 0,33$ & $0,86 \pm 0,54$ & $1,02 \pm 0,59$ & $0,87 \pm 0,57$ \\
T4-24h & $0,68 \pm 0,30$ & $0,76 \pm 0,56$ & $0,89 \pm 0,24$ & $0,67 \pm 0,27$ \\
T5 - 48h & $0,89 \pm 0,50$ & $0,49 \pm 0,36$ & $1,09 \pm 0,58$ & $0,65 \pm 0,41$ \\
T6 - 72h & $0,78 \pm 0,29$ & $0,80 \pm 0,46$ & $1,07 \pm 0,27$ & $0,96 \pm 0,35$ \\
\hline
\end{tabular}

Não houve diferença significativa entre tempos e entre grupos submetidos à transformação logarítmica (monócitos) e à análise de variância e ao teste Tukey $(\mathrm{P}>0,05)$.

\section{CONCLUSÕES}

O veneno de Tityus serrulatus na dose de $250 \mu \mathrm{g} / \mathrm{kg}$ causa aumento do número de hemácias, hematócrito e hemoglobina, além de leucocitose com neutrofilia em cães, provavelmente devido à ação de catecolaminas.

\section{AGRADECIMENTOS}

Agradecimento Especial à Fundação de Amparo à Pesquisa do Estado de Minas Gerais (FAPEMIG) e ao Conselho Nacional de Desenvolvimento Científico e Tecnológico (CNPq).

\section{REFERÊNCIAS BIBLIOGRÁFICAS}

ANDRADE, M.V.; CARAMEZ, M.P.; ABREU, E.M.N.N. et al. Lung compliance, plasma electrolyte levels and acid-base balance are affected by scorpion envenomation in anesthetized rats under mechanical ventilation. Comp. Biochem. Physiol., Part C, v.138, p.97104, 2004.

BERTAZZI, D.T.; ASSIS-PANDOCHI, A.I.; SEIXAS, A.E.C. et al. Effects of Tityus serrulatus scorpion venom and its major toxin, TsTX-I, on the complement system in vivo. Toxicon, v.41, p.501-508, 2003.

BUCARETCHI, F.; BARACAT, C.E.; NOGUEIRA, R.J.N. A comparative study of 
severe scorpion envenomation in children caused by Tityus bahiensis and Tityus serrulatus. Rev. Inst. Med. Trop. São Paulo, v.37, p.331-336, 1995.

BÜCHERL W. Escorpionismo no Brasil. Mem. Inst. Butantan, v.34, p.9-24, 1969.

CAMPOLINA, D. Georreferencimento e estudo clínico-epidemiológico dos acidentes escorpiônicos atendidos em Belo Horizonte, no Serviço de Toxicologia de Minas Gerais. 2006. 127f. Dissertação (Mestrado) - Faculdade de Medicina, Universidade Federal de Minas Gerais, Belo Horizonte.

CORDEIRO, F.F.; SAKATE, M.; FERNANDES $\mathrm{V}$. et al. Clinical and cardiovascular alterations produced by scorpions envenomation in dogs. $J$. Venom. Anim. Toxins, v.12, p.19-43, 2006.

CUPO, P.; AZEVEDO-MARQUES, M.M.; HERING, S.E. Escorpionismo. In: CARDOSO, J.L.C.; FRANÇA, F.O.S.; FAN, H.W. et al. Animais peçonhentos no Brasil: Biologia clínica e terapêutica dos acidentes. São Paulo: Salvier, 2003. p.198-208.

CUPO, P.; HERING, S.E. Cardiac troponin I release after severe scorpion envenoming by Tityus serrulatus. Toxicon, v.40, p.823-830, 2002.

DODDS, W.J. Hemostasis. In: KANEKO, J.J.; HARVEY, J.W.; BRUSS, M.L. Clinical biochemistry of domestic animals. 5.ed. San Diego: Academic Press, 1997. p.241-283.

D'SUZE, G.; MONCADA, S.; GONZÁLEZ, C. et al. Relationship between plasmatic levels of various cytokines, tumour necrosis factor, enzymes, glucose and venom concentration following Tityus scorpion sting. Toxicon, v.41, p.367-375, 2003.

EL-ASMAR, M.F. Metabolic effect of scorpion venom. In: TU, A.T (Ed). Handbook of natural toxins, insects, poisons, allergens and other invertebrate venoms. New York: Marcel Dekker, 1984. v.2, p.551-575.

FAGLIARI, J.J.; PASSIPIERI, M.; OKUDA, H.T. et al. Serum protein concentrations including acute phase proteins, in calves with hepatogenous photossensibilization. Arq. Bras. Med. Vet. Zootec., v.59, p.1355-1358, 2007.

FAGLIARI, J.J.; SILVA, S.L.; SILVA, P.C. et al. Leucograma e teores plasmáticos de proteínas de fase aguda portadores de abdomen agudo e submetidos à laparotomia. Arq. Bras. Med. Vet. Zootec., v.60, p.322-328, 2008.

FUKUHARA, Y.D.M.; REIS, M.L.; DELLALIBERA-JOVILIANO R. et al. Increased plasma levels of IL-1 $\beta$, IL-6, IL-8, IL10 , and TNF- $\alpha$ in patients moderately or severely envenomed by Tityus serrulatus scorpion sting. Toxicon, v.41, p.49-55, 2003.

GAZARIAN, K.G.; GAZARIAN, T.; HERNÁNDEZ, $R$. et al. Immunology of scorpion toxins and perspectives for generation of anti-venom vaccines. Vaccine, v.23, p.33573368, 2005.

ISMAIL, M. The scorpion envenoming syndrome. Toxicon, v.33, p.825-858, 1995.

JAIN, N.C. Essentials of veterinary hematology. Philadelphia: Lea \& Febiger. 1993. 417p.

LONGENECKER, G.L.; LONGENECKER, H.E. Centruroides sculpturatus venom and platelet reactivity: possible role in scorpion venom induced defibrination syndrome. Toxicon, v.19, p.153-157, 1981.

MAGALHÃES, M.M.; PEREIRA, M.E.S.; AMARAL, C.F.S. et al. Serum levels of cytokines in patients envenomed by Tityus serrulatus scorpion sting. Toxicon, v.37, p.11551164, 1999.

MANUAL de diagnóstico e tratamento de acidentes por animais peçonhentos. Brasília: Fundação Nacional da Saúde, 2001. 120p.

MEKI，A.R.M.A.; EL-DEAN, Z.M.M. Serum interleukin- $1 \beta$, interleukin- 6 , nitric oxide and $\alpha 1$ antitrypsin in scorpion envenomed children. Toxicon, v.36, p.1851-1859, 1998.

OLIVEIRA, N.J.F.; MELO, M.M.; LARA, E.R. et al. Perfil clínico e imunológico de bovinos experimentalmente inoculados com veneno bruto e iodado de B. alternatus. Arq. Bras. Med. Vet. Zootec., v.59, p.569-576, 2007.

PETRICEVICH, V.L.; CRUZ, A.H.; CORONAS, F.I.V. et al. Toxin gamma from Tityus serrulatus scorpion venom play na essential role in immunomodulation of macrophages. Toxicon, v.50, p.666-675, 2007.

SAMPAIO, I.B.M. Estatística aplicada à experimentação animal. 3.ed. Belo Horizonte: 
Fundação de Ensino e Pesquisa em Medicina Veterinária e Zootecnia, 2007. 264p.

SAQUETTI, C.H.C.; FALEIROS, R.R., MARCORIS, D.G. et al. Perfil eletroforético do proteinograma sérico de equinos com obstrução experimental do cólon menor. Arq. Bras. Med. Vet. Zootec., v.60, p.794-799, 2008.

SISTEMA de análises estatísticas e genéticas SAEG. Versão 8.0. Viçosa: UFV, 1998.
SOARES, M.R.M.; AZEVEDO, C.S.; MARIA, M. Escorpionismo em Belo Horizonte, MG: um estudo retrospectivo. Rev. Soc. Bras. Med. Trop., v.35, p.359-363, 2002.

TARASIUK, A.; SOFER, S. Effects of adrenergic-receptor blockade and ligation of spleen vessels on the hemodynamics of dogs injected with scorpion venom. Crit. Care Med., v.25, p.365-372, 1999. 